\title{
DESIGN AND SIMULATION OF A RESORBABLE BONE FIXATION PLATE MADE BY ADDITIVE MANUFACTURING FOR FEMORAL MID-SHAFT FRACTURES
}

\author{
J. Ivorra-Martinez ${ }^{\circledR a, *}$, M.A. Selles ${ }^{\circledR a}$, S. Sanchez-Caballero ${ }^{\oplus b}$, T. Boronat ${ }^{\oplus a}$ \\ aMaterials Technology Institute, Universitat Politècnica de València, 03801 Alcoy, Spain. \\ bInstitute of Design for Manufacturing, Universitat Politècnica de València, 03801 Alcoy, Spain.
}

\begin{abstract}
:
Finite element method has been employed to establish the feasibility of a fixation plate made of PLA by additive manufacturing for femoral shaft fractures. For this purpose, Von Mises stress and the pressure contact between bones had been analysed. The proposed design has been compared with an actual titanium fixation plate as a point of reference.

Keywords: femur, mid-SHAFT, finite element method, resorbable, 3D printing.

Cite as: Ivorra-Martinez, J., Selles, M.A., Sanchez-Caballero, S., Boronat, T. (2021). Design and simulation of a resorbable bone fixation plate made by additive manufacturing for femoral MID-shaft fractures. J Appl Res Eng Technol \& Engineering, 2(1), 11-16. https://doi.org/10.4995/jarte.2021.14712
\end{abstract}

\section{Introduction}

Femoral shaft fractures have an incidence of between 10 and 37 per 100,00 patients each year. Some of the main causes of this type of fracture are high-energy impacts as a result of car accidents or falls (K.J. Wu et al., 2019). The treatment usually requires a surgical intervention to introduce a fixation device to ensure stability during the healing process (C. Wu et al., 2020).

The addition of a fixation device acts as a bridge in the fracture, so the loads are transferred by the fixation plate (Heimbach et al., 2017). As a result, the bone surrounding the fixation plate is underloaded compared to its natural state, which leads to a stress shielding process (Arabnejad et al., 2017). Bones are a living tissue and consequently they will adapt to new loads through a process called remodelling (George et al., 2017), which leads to the reduction of its density (Ridzwan et al., 2006). As a result of the loss of density in the bone, the mechanical properties will deteriorate resulting in a future fracture (Heimbach et al., 2017; X. Wu et al., 2019).

The most common materials used for the manufacture of fixation plates are pure titanium or titanium alloys such as Ti-6Al-A4. These types of materials show a higher modulus of elasticity than human bone, resulting in a stress shielding process (Guastaldi et al., 2019; Junlei Li et al., 2020). Stainless steel is another material widely used for bone fixation but with less biocompatibility and corrosion resistance (Geetha et al., 2009). In recent years, the possibility of using biopolymers in biomedicine has been investigated with excellent results (AlizadehOsgouei etal., 2019). One of the most interesting biopolymers is PLA, some of the properties that make it a suitable material are excellent biocompatibility, easy to manufacture or hydrophobic in nature (Jiafeng Li et al., 2017; Narayanan et al., 2016).The ability to degrade within the human body is an interesting property as it avoids a second surgical intervention to remove the fixation plate, the device degrades by body fluids and is reabsorbed by the body (Kanno et al., 2018).

The use of biopolymers such as PLA is closely related to additive manufacturing techniques (AM) such as fussed deposition modelling (FDM). These techniques allow the manufacture of different geometries without using complex equipment (Parthasarathy et al., 2015), thus reducing costs (Singh et al., 2018). Another advantage of AM is the possibility of producing a custom fixation device for the patient (Murr et al., 2016; X. Wang et al., 2016), for which Computerized Tomography (CT) helps to create a solid 3D model of a bone that can be used as the basis for designing the fixation plate (Liu et al., 2019).

The main objective of this work is to evaluate the viability of the PLA resorbable bone fixation plate made by fusion deposition modelling. For this purpose, the PLA bone fixation plate is compared with titanium by using finite element analysis (FEA). This is done by analysing the pressure and displacement applied in the fracture area, as well as the resulting stress on the fixation plate.

\section{Materials and methods}

\subsection{Finite element modelling}

The two proposed models consist of a fracture of the femoral shaft with two types of fixation plates, a standard titanium and another 3D printed PLA (Figure 1). The dimensions of the titanium plates were $17.5 \mathrm{~mm}$ wide, $5 \mathrm{~mm}$ thick, $178 \mathrm{~mm}$ long and 10 holes of $4.5 \mathrm{~mm}$ according to the specifications proposed by the TIPSAN catalogue (TIPSAN, Bornova, Turkey). A thickness of 
$5 \mathrm{~mm}$ is also considered for the modelling of the PLA plate. Simplified screws (Figure 3) (of the same material as the plate) are used for placement in the bone. For the idealization of the femur, a cylinder is considered as cancellous bone and a tube as cortical bone (Figure 2). The dimensions considered in the model were for an average man of 50 years old (Table 1). The solid parts had different linear isotropic properties and are represented in Table 2

In order to ensure the correct stability of the fracture during the recuperation, the mechanical properties along the time were tested. To this propose, the properties of degraded PLA after 30 days inside human body had been considered. Spiridon et al. proposed that PLA immersed in simulated body fluid (SBF) during one month, will lose about $22.8 \%$ of its Young modulus and $32.9 \%$ of its tensile strength (Spiridon et al., 2018).

The geometry was meshed using Siemens NX 12.0, (Siemens, Munich, Germany) with 3D elements CTETRA(10) with 10 nodes for each element. The number of elements in each part was 160,320 for cortical bone, 102,201 for cancellous bone, 21,547 for each screw, 437,149 for PLA and 152,687 for titanium.
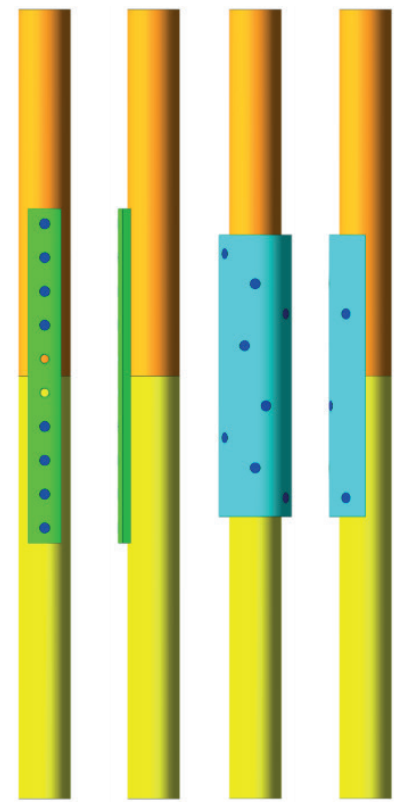

Figure 1: 3D model of femur shaft fracture with fixation plate titanium (green), PLA (blue).
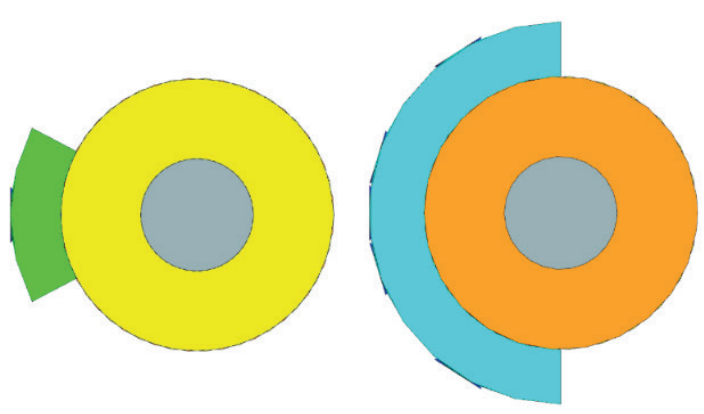

Figure 2: Femur section with fixation plate, titanium (green), PLA (blue).
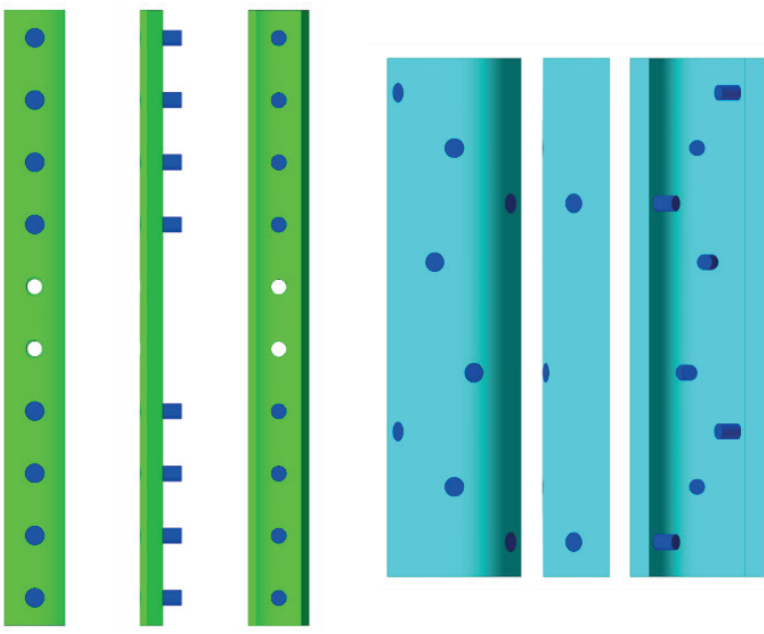

Figure 3: Fixation plates with screws, titanium (green), PLA (blue).

Table 1: Dimensions for femur model.

\begin{tabular}{lcc}
\hline Dimension & Value & Reference \\
\hline Length & $450 \mathrm{~mm}$ & (Klein et al., 2015) \\
\hline Total bone section & $650 \mathrm{~mm}^{2}$ & (Klein et al., 2015) \\
Cortical bone section & $500 \mathrm{~mm}^{2}$ & (Klein et al., 2015) \\
Head femur offset & $42.2 \mathrm{~mm}$ & (Sariali et al., 2009) \\
\hline
\end{tabular}

Table 2: Isotropic properties of materials.

\begin{tabular}{|c|c|c|c|c|}
\hline Material & $\begin{array}{c}\text { Elastic } \\
\text { Modulus } \\
(\mathrm{MPa})\end{array}$ & $\begin{array}{l}\text { Tensile } \\
\text { strength } \\
\text { (MPa) }\end{array}$ & $\begin{array}{l}\text { Poisson's } \\
\text { ratio }\end{array}$ & Reference \\
\hline Cortical bone & 16350 & - & 0.26 & $\begin{array}{c}\text { (Jia Li, et al., } \\
2019)\end{array}$ \\
\hline $\begin{array}{l}\text { Cancellous } \\
\text { bone }\end{array}$ & 137 & - & 0.30 & $\begin{array}{c}\text { (Jia Li, et al., } \\
\text { 2019) }\end{array}$ \\
\hline Titanium & 110000 & 920 & 0.34 & $\begin{array}{c}\text { (Nurettin et al., } \\
\text { 2018; Zhao } \\
\text { et al., 2012) }\end{array}$ \\
\hline PLA & 3368 & 56.6 & 0.30 & $\begin{array}{c}\text { (Tymrak et al., } \\
2014)\end{array}$ \\
\hline PLA-30 days & 2702 & 37.9 & 0.30 & $\begin{array}{c}\text { (Spiridon et al., } \\
\text { 2018; Tymrak } \\
\text { et al., 2014) }\end{array}$ \\
\hline
\end{tabular}

\subsection{Contact surfaces}

The contacts between the different bodies ensure the correct transfer of load between them. In order to reduce the computational cost, frictionless contacts were established between the bone plate and the plate screw. Only the contact in the fractured area was modelled with a friction coefficient of 0.46 as proposed by Wang et al. (Wang et al., 2020), so that the displacement on the contact surfaces can be stablished. Finally, the screws were attached to the cortical bone because the focus of the study was on the fixation plate.

\subsection{Boundary and loading conditions}

For the simulation, a fixed support was applied at the base ( 0 degree of freedom) and a $1400 \mathrm{~N}$ compression force was applied at the top. The load represents a single-leg 
standing position as Wang et al. and McClellan et al. proposed (McClellan et al., 2013; Wang et al., 2006). This load should be applied on the femur head (Figure 4), since the model was simplified and the femur head was not modelled, the force was applied on one node (where femoral head should be) and connected with bone by a rigid region RBE2.

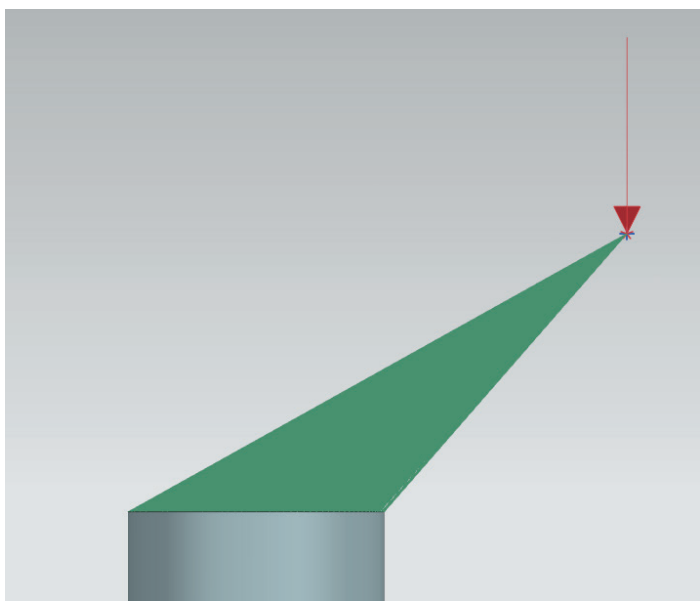

Figure 4: Load application on the rigid region.

\section{Results and discussion}

\subsection{Fracture surface contact results}

Ensuring the fracture healing process is the most important parameter of this study. For this purpose, the mobility and the pressure applied on the fracture surface are the main factors. While the longitudinal strain applied to fractures was shown to promote the healing process (Elkins et al., 2016), mobility at the fracture site disturbs callus formation (Jahagirdar et al., 2009). For this purpose, a friction contact between the bone fragments was established and the resulting pressure and displacement after the force was applied was analysed.

The femur undergoes at flexural tensile state by the loads applied, in this case the compressive area corresponds to right part and the traction area corresponds to the left. The fixation plate was placed on the left (traction) to avoid bone separation. Titanium fixation plate acts as a point of reference, this kind of plates are widely applied in traumatology surgeries (Hayes et al., 2010; Junlei $\mathrm{Li}$ et al., 2020). The pressure distribution in titanium model (Figure 5 up-right) shows a maximum pressure of 34.0 MPa and progressively decreases until $0 \mathrm{MPa}$.

The results when using PLA are quite similar, but in this case the maximum pressure is $28.8 \mathrm{MPa}$. An interesting result is in the cancellous bone, in this case the pressure is close to $0 \mathrm{MPa}$ due to the difference between the elastic modulus of both types of bones (the cortical bone is approximately 120 times stiffer than cancellous bone). In order to achieve these results, the 3D printed PLA section was modelled with a higher section.

The force applied to the top generates a shear stress on the contact surfaces that promotes de displacement. Since the contact was modelled as frictional, the area where more pressure is applied, displacement is avoided. The area where pressure tends to 0 , the frictional forces cannot prevent the displacement and therefore a small displacement appears. However, in both cases the displacements are quite close to $0 \mathrm{~mm}$ (about $10^{-5} \mathrm{~mm}$ ).

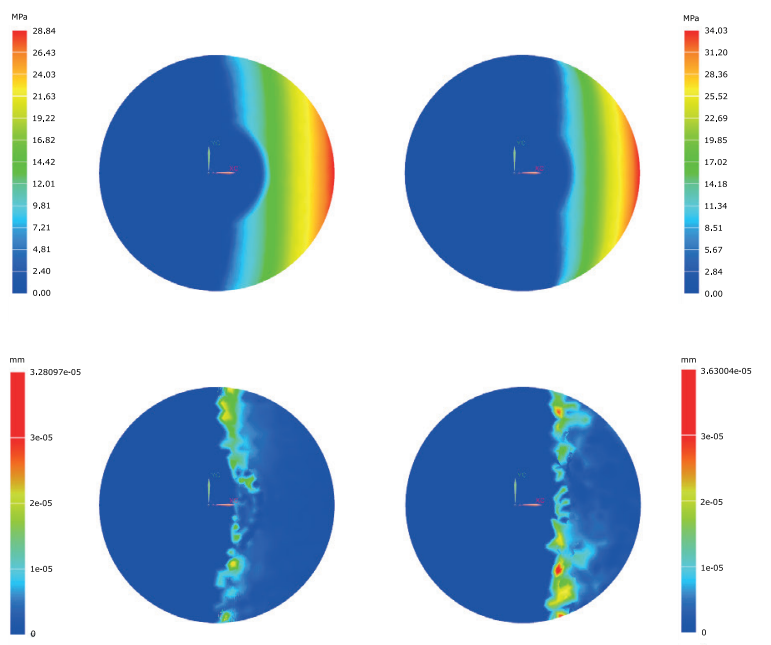

Figure 5: Pressure in MPa (up) and displacement in $\mathrm{mm}$ (down), 3D printed PLA (left) and Titanium (right).

Kim et al. (Kim et al., 2012) predicted the healing process for different fixation plates. In all cases the bone formation started from the site where more pressure was applied during the loading.

\subsection{Von Mises stress}

Another important parameter to avoid the failure of the medical device is the distribution of stress. The results of the FEM (Figure 6) indicated that in both cases the maximum tensile strengths was located around the holes due to the contact between the screw and the fixation plate. In those cases, the screws acted as a transmission element between the bone and the fixation plate.

For the titanium fixation plate, the maximum Von Misses stress was 739.6 MPa (under tensile strength) in the top hole while most of the elements were below $47 \mathrm{MPa}$. In the case of the screw, the maximum stress appears near where the contact changes from screw/bone for screw/ fixation plate. In addition, another area of maximum stress was induced by the screw head stress concentrator.

Different results were obtained for PLA, where the maximum Von Misses stress was 51.9 MPa. For this, the design of the fixation plate introduced some modifications with respect to the standard of titanium, although the number of screws is the same, they were distributed throughout the area. The modification allowed a better stability in the fractured area and a reduction of the Von Misses stress.

Tang et al. (Tang et al., 2013) obtained a Von Mises stress $130.2 \mathrm{MPa}$ with $250 \mathrm{~N}$ load. In a linear model, if the same load was applied, the resulting stress would be about $730 \mathrm{MPa}$. 


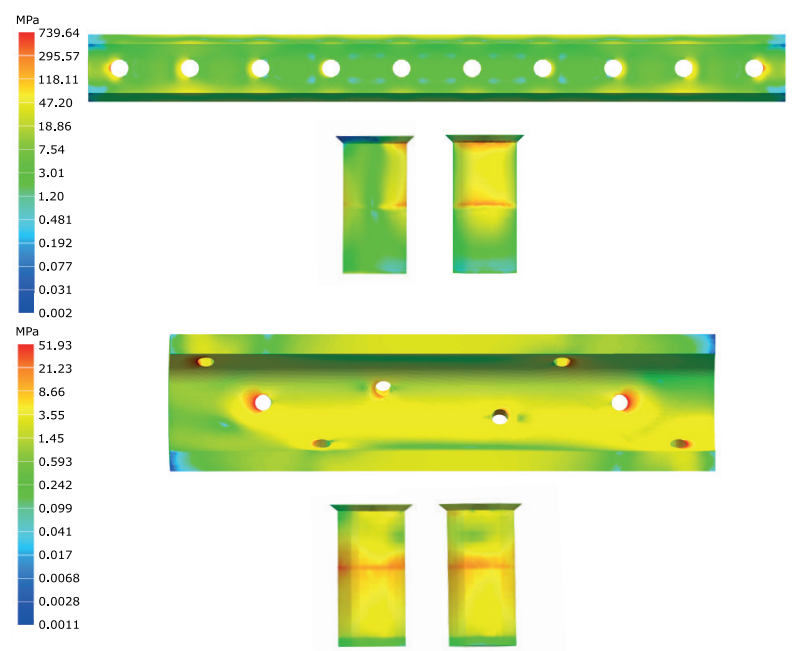

Figure 6: Von Mises stress (MPa) distribution for titanium (up) and $3 \mathrm{D}$ printed PLA (down)

\subsection{Effect of the degradation on PLA}

The previous model has been re-simulated with the PLA properties after 30 day in SBF. The main assumption is that the only difference between a new PLA-fixation plate and a degraded one is the effect on the mechanical properties proposed in Table 2.

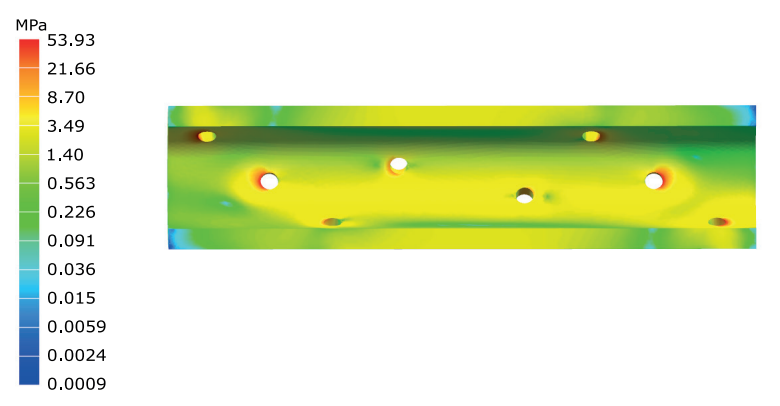

Figure 7: Von Mises stress distribution for 30 days degradation PLA.

The proposed results in Figure 7 showed an increase in Von Mises stress due to the decease on Young modulus. In this situation the maximum Von Mises stress was 53.9 MPa, a $3.9 \%$ increase in stress compared to the new PLA fixation plate. Under these conditions, the device would break due to the tensile strength after 30 day in SBF is about $37.9 \mathrm{MPa}$.
A problem without no-linear effects, the increase of stress would be equivalent to the reduction of Young modulus. In this case, the contact pressure between the ends of the bone produced a no-linear effect. As can be seen in Figure 8, the pressure contact increased from 28.84 MPa with a nondegraded devices to $29.88 \mathrm{MPa}$ after 30 day implantation.
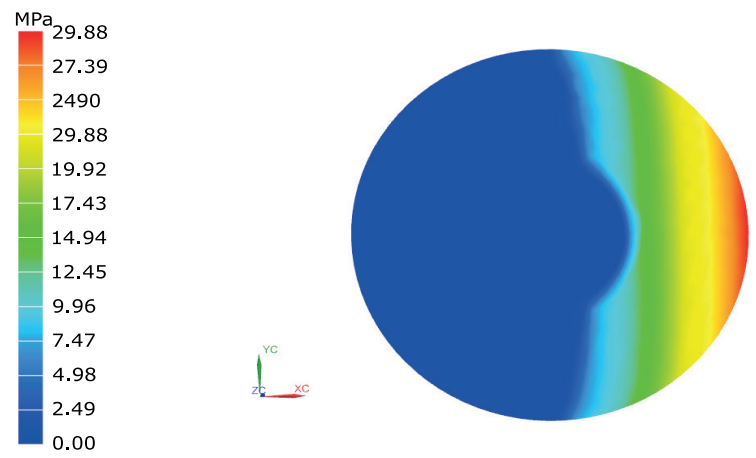

Figure 8: Pressure contact distribution for 30 days degradation PLA.

\section{Conclusions}

In this work, the main objective was to study the feasibility of the 3D printed PLA femoral fixation plate. In comparison with a titanium fixation plate, similar results were obtained in the contact of the fracture surface, making possible the bone regeneration process.

PLA properties over the time take an important role on the correct functionality of the fixation plate. Even the stress results on a new fixation plate were positive, after 30 day of degradation the fixation plate would brake under the proposed load. To this effect, the utilization of additives could help to control the loss of properties inside the human body.

One important aspect is that the patient activity would not be recovered during the recuperation. This means that the patient should not be on a single standing leg over this period. Nevertheless, the results, suggest that other bones with less load could be treated with this kind of fixation plate.

\section{Acknowledgements}

J. Ivorra-Martinez is funded with a Formación de Profesorado Universitario (FPU) grant from the Spanish Government (Ministerio de Ciencia, Innovación y Universidades), with reference FPU19/01759.

\section{References}

Alizadeh-Osgouei, M., Li, Y., Wen, C. (2019). A comprehensive review of biodegradable synthetic polymerceramic composites and their manufacture for biomedical applications. Bioactive materials, 4(1), 22-36. https://doi.org/10.1016/j.bioactmat.2018.11.003

Arabnejad, S., Johnston, B., Tanzer, M., Pasini, D. (2017). Fully porous 3D printed titanium femoral stem to reduce stress-shielding following total hip arthroplasty. Journal of Orthopaedic Research, 35(8), $1774-1783$. https://doi.org/10.1002/jor.23445 
Elkins, J., Marsh, J.L., Lujan, T., Peindl, R., Kellam, J., Anderson, D D., \& Lack, W. (2016). Motion predicts clinical callus formation: construct-specific finite element analysis of supracondylar femoral fractures. The Journal of bone and joint surgery. American volume, 98(4), 276. https://doi.org/10.2106/JBJS.0.00684

Geetha, M., Singh, A.K., Asokamani, R., Gogia, A.K. (2009). Ti based biomaterials, the ultimate choice for orthopaedic implants-a review. Progress in materials science, 54(3), 397-425. https://doi.org/10.1016/j.pmatsci.2008.06.004

George, D., Allena, R., Remond, Y. (2017). Mechanobiological stimuli for bone remodeling: mechanical energy, cell nutriments and mobility. Computer Methods in Biomechanics and Biomedical Engineering, 20(sup1), S91-S92, https://doi.org/10.1080/10255842.2017.1382876

Guastaldi, F., Martini, A., Rocha, E., Hochuli-Vieira, E., Guastaldi, A. (2019). Ti-15Mo Alloy Decreases the Stress Concentration in Mandibular Angle Fracture Internal Fixation Hardware. Journal of Maxillofacial and Oral Surgery, 19, 314-320. https://doi.org/10.1007/s12663-019-01251-8

Hayes, J., Richards, R. (2010). The use of titanium and stainless steel in fracture fixation. Expert review of medical devices, 7(6), 843-853. https://doi.org/10.1586/erd.10.53

Heimbach, B., Grassie, K., Shaw, M.T., Olson, J.R., Wei, M. (2017). Effect of hydroxyapatite concentration on highmodulus composite for biodegradable bone-fixation devices. Journal of Biomedical Materials Research Part B: Applied Biomaterials, 105(7), 1963-1971. https://doi.org/10.1002/jbm.b.33713

Jahagirdar, R., Scammell, B.E. (2009). Principles of fracture healing and disorders of bone union. Surgery (Oxford), 27(2), 63-69. https://doi.org/10.1016/j.mpsur.2008.12.011

Kanno, T., Sukegawa, S., Furuki, Y., Nariai, Y., Sekine, J. (2018). Overview of innovative advances in bioresorbable plate systems for oral and maxillofacial surgery. Japanese Dental Science Review, 54(3), $127-138$. https://doi.org/10.1016/j.jdsr.2018.03.003

Kim, H.J., Chang, S.H., Jung, H.J. (2012). The simulation of tissue differentiation at a fracture gap using a mechanoregulation theory dealing with deviatoric strains in the presence of a composite bone plate. Composites Part $B$ : Engineering, 43(3), 978-987. https://doi.org/10.1016/j.compositesb.2011.09.011

Klein, K.F., Hu, J., Reed, M.P., Hoff, C.N., Rupp, J.D. (2015). Development and validation of statistical models of femur geometry for use with parametric finite element models. Annals of biomedical engineering, 43(10), $2503-2514$. https://doi.org/10.1007/s10439-015-1307-6

Li, J., Li, Z., Ye, L., Zhao, X., Coates, P., Caton-Rose, F. (2017). Structure and biocompatibility improvement mechanism of highly oriented poly (lactic acid) produced by solid die drawing. European Polymer Journal, 97, 68-76. https://doi.org/10.1016/j.eurpolymj.2017.09.038

Li, J., Qin, L., Yang, K., Ma, Z., Wang, Y., Cheng, L., Zhao, D. (2020). Materials evolution of bone plates for internal fixation of bone fractures: A review. Journal of Materials Science \& Technology, 36, $190-208$. https://doi.org/10.1016/j.jmst.2019.07.024

Li, J., Yin, P., Zhang, L., Chen, H., Tang, P. (2019). Medial anatomical buttress plate in treating displaced femoral neck fracture a finite element analysis. Injury, 50(11), 1895-1900. https://doi.org/10.1016/j.injury.2019.08.024

Liu, B., Zhang, S., Zhang, J., Xu, Z., Chen, Y., Liu, S., Yang, L. (2019). A personalized preoperative modeling system for internal fixation plates in long bone fracture surgery-A straightforward way from CT images to plate model. The International Journal of Medical Robotics and Computer Assisted Surgery, 15(5), e2029. https://doi.org/10.1002/rcs.2029

McClellan, R.T. (2013). The variable angle hip fracture nail relative to the Gamma 3: A finite element analysis illustrating the same stiffness and fatigue characteristics. Advances in orthopedics, 2013. https://doi.org/10.1155/2013/143801

Murr, L.E. (2016). Frontiers of 3D printing/additive manufacturing: from human organs to aircraft fabrication. Journal of Materials Science \& Technology, 32(10), 987-995. https://doi.org/10.1016/j.jmst.2016.08.011

Narayanan, G., Vernekar, V.N., Kuyinu, E.L., Laurencin, C.T. (2016). Poly (lactic acid)-based biomaterials for orthopaedic regenerative engineering. Advanced drug delivery reviews, 107, 247-276. https://doi.org/10.1016/j.addr.2016.04.015

Nurettin, D., Burak, B. (2018). Feasibility of carbon-fiber-reinforced polymer fixation plates for treatment of atrophic mandibular fracture: A finite element method. Journal of Cranio-Maxillofacial Surgery, 46(12), $2182-2189$. https://doi.org/10.1016/j.jcms.2018.09.030

Parthasarathy, J. (2015). 14 Additive Manufacturing of Medical Devices. Additive Manufacturing: Innovations, Advances, and Applications, 369. 
Ridzwan, M., Shuib, S., Hassan, A., Shokri, A., Ibrahim, M. (2006). Optimization in implant topology to reduce stress shielding problem. Journal of Applied Sciences, 6(13), 2768-2773. https://doi.org/10.3923/jas.2006.2768.2773

Sariali, E., Mouttet, A., Pasquier, G., Durante, E. (2009). Three-dimensional hip anatomy in osteoarthritis: analysis of the femoral offset. The Journal of arthroplasty, 24(6), 990-997. https://doi.org/10.1016/j.arth.2008.04.031

Singh, D., Singh, R., Boparai, K.S. (2018). Development and surface improvement of FDM pattern based investment casting of biomedical implants: A state of art review. Journal of Manufacturing Processes, 31, 80-95. https://doi.org/10.1016/j.jmapro.2017.10.026

Spiridon, I., Tanase, C.E. (2018). Design, characterization and preliminary biological evaluation of new lignin-PLA biocomposites. International journal of biological macromolecules, 114, 855-863. https://doi.org/10.1016/j.ijbiomac.2018.03.140

Tang, G., Liu, S.L., Wang, D.M., Wei, G.F., Wang, C.T. (2013). Finite element analysis in femoral fixation with TA3 titanium compressioll plate. In Advanced Materials Research, 647, 16-19. Trans Tech Publications Ltd. https://doi.org/10.4028/www.scientific.net/AMR.647.16

Tymrak, B., Kreiger, M., Pearce, J.M. (2014). Mechanical properties of components fabricated with open-source 3-D printers under realistic environmental conditions. Materials \& Design, 58, 242-246. https://doi.org/10.1016/j.matdes.2014.02.038

Wang, A.Y., Peng, J., Sun, M.X., Sui, X., Wang, X., Tian, Y., Lu, S.B. (2006). Biomechanical comparison of different structural bone grafting in femoral heads' defects of weight-bearing region. Journal of Medical Biomechanics, 4.

Wang, J., Ma, J.X., Lu, B., Bai, H.H., Wang, Y., Ma, X.L. (2020). Comparative finite element analysis of three implants fixing stable and unstable subtrochanteric femoral fractures: Proximal Femoral Nail Antirotation (PFNA), Proximal Femoral Locking Plate (PFLP), and Reverse Less Invasive Stabilization System (LISS). Orthopaedics \& Traumatology: Surgery \& Research, 106(1), 95-101. https://doi.org/10.1016/j.otsr.2019.04.027

Wang, X., Xu, S., Zhou, S., Xu, W., Leary, M., Choong, P., Xie, Y.M. (2016). Topological design and additive manufacturing of porous metals for bone scaffolds and orthopaedic implants: A review. Biomaterials, 83, $127-141$. https://doi.org/10.1016/j.biomaterials.2016.01.012

Wu, C., Zheng, K., Fang, J., Steven, G.P., Li, Q. (2020). Time-dependent topology optimization of bone plates considering bone remodeling. Computer Methods in Applied Mechanics and Engineering, 359, 112702. https://doi.org/10.1016/j.cma.2019.112702

Wu, K.J., Li, S.H., Yeh, K.T., Chen, H., Lee, R.P., Yu, T.C., Wang, J.H. (2019). The risk factors of nonunion after intramedullary nailing fixation of femur shaft fracture in middle age patients. Medicine, 98(29). https://doi.org/10.1097/MD.0000000000016559

Wu, X., Wang, Z., Li, H., Li, Y., Wang, H., Tian, W. (2019). Biomechanical evaluation of osteoporotic fracture: Metal fixation versus absorbable fixation in Sawbones models. Injury, 50(7), 1272-1276. https://doi.org/10.1016/j.injury.2019.05.023

Zhao, X., Niinomi, M., Nakai, M., Hieda, J., Ishimoto, T., Nakano, T. (2012). Optimization of Cr content of metastable $\beta$-type Ti-Cr alloys with changeable Young's modulus for spinal fixation applications. Acta biomaterialia, 8(6), $2392-2400$. https://doi.org/10.1016/j.actbio.2012.02.010 